\title{
Role and Place of Nurses with Master's Degree in Practical Healthcare and Medical Education
}

\author{
V. Zabolotnov (Vitaliy Aleksadrovich Zabolotnov)'1, 0. Khitrich (Olena Borysivna \\ Khitrich)2, O. Antonov (Oleksii Volodymyrov Antonov)', J. Stanciak (Jaroslav \\ Stanciak) ${ }^{1}$
}

${ }^{1}$ Municipal Higher Educational Institution,

Original Article

Zhytomyr Medical Institute of Zhytomyr Regional Government, UA

${ }^{2}$ Comenius University in Bratislava, Faculty of Education, Bratislava, SK

\section{E-mail address:}

j.stanciak@gmail.com

\section{Reprint address:}

Jaroslav Stanciak

Faculty of Education

Racianska 59

81334 Bratislava, SK

Source: Clinical Social Work and Health Intervention Pages: $36-43$
Volume: 9

Issue: 3

\section{Reviewers:}

Vlastimil Kozon - vlastimil.kozon@univie.ac.at

Maria Hardy - hardy@sopza.sk

\section{Key words:}

Nursing. Healthcare. Higher degree-based education.

\section{Publisher:}

International Society of Applied Preventive Medicine i-gap

CSWHI 2018; 9(3): 36 - 43; DOI 10.22359/cswhi_9_3_04 @ 2018 Clinical Social Work and Health Intervention

\section{Abstract:}

The aim of the research was to distinguish the roles, fields of work and organizational skills of Nurses with Master's Degree in Practical Health Care and Education in Ukraine. 95 Nurses were surveyed in order to achieve the goals of the research (Nurses with Master's Degree (MD), Nurses without Master's Degree and MD Teachers). It is proved, that a Nurse with an MD is a highly qualified Specialist who gained in-depth 
special knowledge, skills and possesses necessary experience for their usage. Also, such a Nurse acts as a leader and takes professional responsibility in every possible area of activity. We consider unacceptable the fact, that the majority of MD teachers do not work in Medical Institutions and do not have the opportUnity to constantly improve the professional level of Nursing. Nursing Specialists in Ukraine believe, that the time has come to implement the concept of the development of Higher Nursing Education and insist on the creation of certain favorable conditions for continuing education and obtaining the third educational-scientific level - the diploma of the Doctor of Philosophy (PhD Degree).

\section{Introduction}

The importance of the work of a Nurse grows in Ukraine [1,2]. The goal of the development of Nursing in Ukraine is to strengthen the health of the population; increase the duration of life and its quality by improving the efficiency of the Healthcare System; expanding coverage of Health and Medical Care Services [3,4,12]. This following goal can be achieved by involving Nurses in expanding the function of healthcare, education, creation of institutions, where services can be provided: Hospices, Nursing Care Departments, Homes, etc $[5,6,15]$. An active formation of the legislative framework in the field of Nursing and the need to accelerate the adaptation of the domestic normative legal base to European norms should be considered to be one the most urging and pressing issues. [14,16].

The most important achievements of Nursing in the overwhelming majority of countries of the world are: development of Nursing as an independent sphere of professional activity in healthcare with a well-established management system; introduction of newest types of Nursing care and assistance; the formation of Nursing as a scientific discipline with scientific research on clinical issues together with the administration within Nursing services; purposeful training of Nursing staff; development and improvement of the multi-level system of Higher Nursing Education which provides differentiated training of Nursing personnel depending on the needs of the market of Medical Services; high social status of a Nurse [7-9].

Determination of the role of a Nurse with a Master's Degree in Ukraine. Identification of the areas and fields of work, organizational skills and abilities of MD Nurses.

\section{Martials and Methods}

95 Nurses have been surveyed. Participants were divided into 3 Groups, age range was within 25-56 years old.

The first Group consisted of Nurses without full Higher Nursing Education (50 participants) who work in the Zhytomyr Regional Children's Clinical Hospital and O.F. Herbachevsky Regional Clinical Hospital (age range - 25-56 years old).

The second Group consisted of MD Nurses (Nurses with Master's Degree - 30 participants), who work in the Zhytomyr Regional Children's Clinical Hospital and O.F. Herbachevsky Regional Clinical Hospital (age range - 25-35 years old).

The third Group consisted of MD Nurses, who work in Zhytomyr Medical Institute as the Teachers (15 participants within age range of 26-35 years old).

A surveying method was used in order to achieve the goal which was accompanied 
by the methods of system analysis and logical generalization. To carry out the analysis of the results of the conducted research, we determine that the Nurses were taken in the selective multistage observation for the general population.

\section{Results and Their Discussion}

In Group I the majority of the participants $(64 \%)$ as well as in the Group II $(80 \%)$ are individuals within age range of 26-35 years old. Group III consisted (53\%) of individuals under 35 years old (Table 1).

We assume, that the prevailing part of Nurses within Group I (50 part.) are eligible to improve their qualification level under certain circumstances. In particular, their colleagues in the same age Group were able to change their occupation and have already been involved in teaching activities.

At the same time, among practicing Nurses with Master's $86 \%$ of them, were forced to carry out the duties of a Junior Specialist with Medical Education due to the lack of individual Nursing Organizational and Managerial Units similar to those existing abroad, a small number of career
Table 1: Age categories of the participants (\%)

\begin{tabular}{|c|c|c|c|c|c|c|}
\hline \multirow[t]{2}{*}{$\begin{array}{l}\text { Age } \\
\text { cate- } \\
\text { gories }\end{array}$} & \multicolumn{2}{|c|}{$\begin{array}{l}\text { Nurses } \\
\text { Without } \\
\text { Master's } \\
\text { Degree }\end{array}$} & \multicolumn{2}{|c|}{$\begin{array}{l}\text { Acting Nur- } \\
\text { ses with } \\
\text { Master's } \\
\text { Degree }\end{array}$} & \multicolumn{2}{|c|}{$\begin{array}{l}\text { Nurses with } \\
\text { Master's } \\
\text { Degree } \\
\text { (Teachers) } \\
\end{array}$} \\
\hline & $\begin{array}{c}\mathrm{Ab}- \\
\text { solute } \\
\text { number }\end{array}$ & $\%$ & $\begin{array}{c}\mathrm{Ab}- \\
\text { solute } \\
\text { number }\end{array}$ & $\%$ & $\begin{array}{c}\text { Ab- } \\
\text { solute } \\
\text { number }\end{array}$ & $\%$ \\
\hline $\begin{array}{c}\text { under } \\
25 \\
\text { years }\end{array}$ & 10 & 20 & 16 & 53 & 1 & 7 \\
\hline $\begin{array}{l}26-35 \\
\text { years }\end{array}$ & 32 & 64 & 11 & 37 & 12 & 80 \\
\hline $\begin{array}{l}36-55 \\
\text { years }\end{array}$ & 8 & 16 & 3 & 10 & 2 & 13 \\
\hline $\begin{array}{l}56 \mathrm{i} \leq \\
\text { years }\end{array}$ & 0 & - & 0 & - & 0 & - \\
\hline Total & 50 & 100 & 30 & 100 & 15 & 100 \\
\hline
\end{tabular}

perspectives requiring such a level of Education (only Deputy Chief Doctor of Nursing) and other reasons. Only $7 \%$ of a total number of Specialists working as a Senior Medical Nurse of the Department, although the post requires higher education, and the same percentage $(7 \%)$ occupies the post of Deputy Chief Nursing Officer (Table. 2).

Table 2: Posts, occupied by the participants

\begin{tabular}{|c|c|c|c|c|c|c|}
\hline \multirow{2}{*}{$\begin{array}{c}\text { Respondents working } \\
\text { in positions }\end{array}$} & \multicolumn{2}{|c|}{$\begin{array}{c}\text { Nurses without } \\
\text { Higher Medical } \\
\text { Education }\end{array}$} & $\begin{array}{c}\text { Practicing Nurses } \\
\text { with Master's } \\
\text { Degree }\end{array}$ & \multicolumn{2}{|c|}{$\begin{array}{c}\text { Nurses with } \\
\text { Master's Degree } \\
\text { (Teachers) }\end{array}$} \\
\cline { 2 - 7 } & $\begin{array}{c}\text { Absolute } \\
\text { number }\end{array}$ & $\%$ & $\begin{array}{c}\text { Absolute } \\
\text { number }\end{array}$ & $\%$ & $\begin{array}{c}\text { Absolute } \\
\text { number }\end{array}$ & $\%$ \\
\hline Post-manipulative Nurse & 50 & 100 & 26 & 86 & - & - \\
\hline $\begin{array}{c}\text { Senior Medical Nurse of } \\
\text { the Department }\end{array}$ & - & - & 2 & 7 & - & - \\
\hline $\begin{array}{c}\text { Deputy Chief Nursing } \\
\text { Officer }\end{array}$ & - & - & 2 & 7 & - & - \\
\hline $\begin{array}{c}\text { Teacher of the } \\
\text { Department in ZMI }\end{array}$ & - & - & - & - & 15 & 100 \\
\hline Total & 50 & 100 & 30 & 100 & 15 & 100 \\
\hline
\end{tabular}


As to the reasons for choosing the profession of „Nurse“, in all three core samples it was "for personal conviction" (from 51\% in Group I; 70\% in Group II and up to 73\% in Group III). However, we must note that the largest proportion of surveyed Masters of Nursing more often, in more than two out of three, chose their profession consciously. A significant proportion of respondents (more than 20\%) in each Group pointed out for another reason - «on the advice of parents and acquaintances". The rest hesitated to answer directly. Group I even contained individuals who have chosen the Medical Institute due to prospects of free education and in accordance to the results of IEE (Independent External Evaluation) (fig. 1).

The general medical experience varies considerably within respondents in Groups I, II and III. So, more than half of the Nurses without Higher Nursing Education (56\%) have practicing experience in the range of $11-20$ years, and $10 \%$ of participants have been working for more then 20 years. In the Group of practicing MD Nurses about 43\% have working experience of 6-10 years; $37 \%$ of them have been working under 5 years possibly due to continuous education.
In Group III $67 \%$ of respondents possessed active experience in Practical Healthcare; 33\% didn't have a proper opportunity to acquire it due to necessity to work in a healthcare institution after receiving a sufficient level of education. During the conduct research, none of the teachers was involved in the practical field of healthcare. Still, $60 \%$ of participants have been working under 5 years and $40 \%$ possess around 6-10 years of working experience which is connected with the legislative regulation of the requirements for Teachers in Medical Colleges, Institutes and the introduction of step-by-step (degree-based) Nursing Education.

The main task of Certification of Nurses is to determine the amount of knowledge; practical skills; level of their possession; ability to use in professional activities; timely professional training; development; efficient issue solving [12]. So, in Group I 32\% of respondents have a Higher Category; first category is possessed by $38 \%$; the second was given to $14 \%$, and $16 \%$ remained uncertified due to lack of experience. In Group II a significant part of Nurses (36\%) doesn't have any category; $30 \%$ possess a second

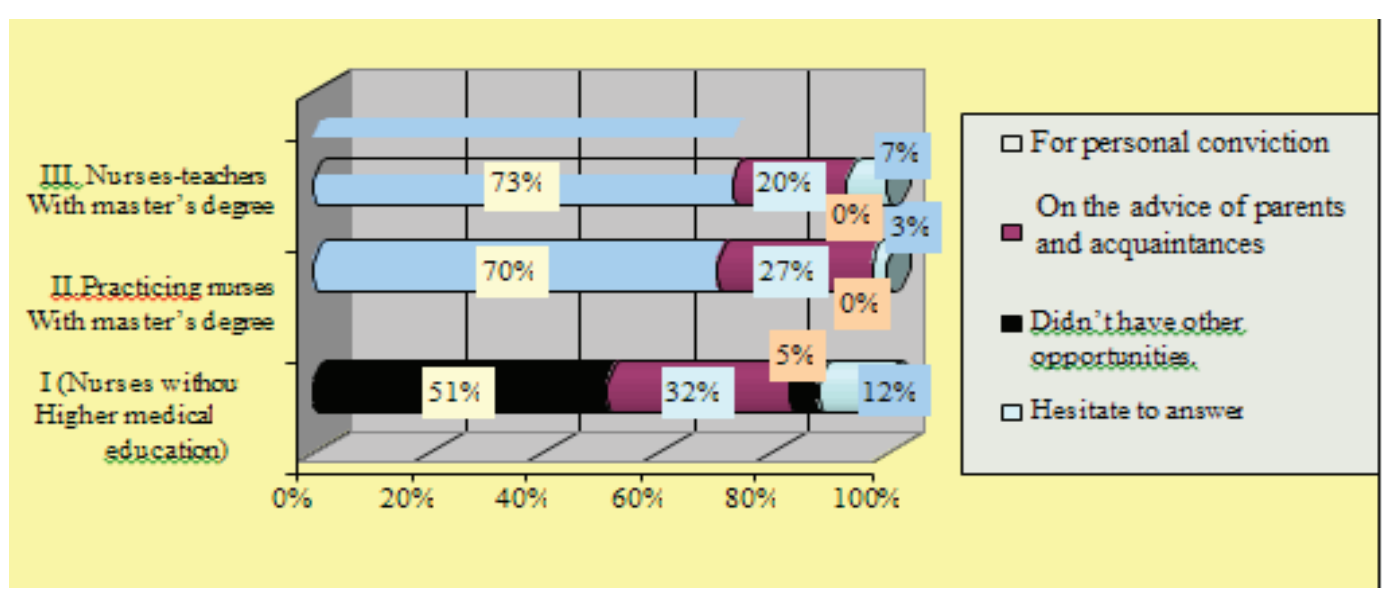

Figure 1: Reasons of Nursing Specialty Selection (\%) 
category; the first and the Higher Categories were given to equal shares of the respondents $-17 \%$. $67 \%$ of participants in Group III have a qualification category obtained in accordance with the requirements of qualification categories and pedagogical titles of Pedagogical Workers and 33\% of respondents still don't have it. There is no Nurse with this particular type of qualification in Group III.

Group I consists of current students of Medical Institutions obtaining a Bachelor Degree by $30 \%, 8 \%$ of whom have plans for further education. It indicates the understanding of the comprehensive role of a Higher Nursing Education and the prospect of her/his manifestation in practice. They have also revealed a zeal for future teaching activity. Besides, $20 \%$ of participants have pointed out that Higher Education could give them opportunity for a possible labor activity profile change.

$13 \%$ of participants from Group II hesitated to give a direct answer, thereby making it clear that they are waiting for certain favorable conditions for continuing education and obtaining a $\mathrm{PhD}$.

$20 \%$ of Group III respondents made it clear, that they have already possessed a Master's Degree in any other field of knowledge except for Nursing. $27 \%$ of participant are planning to continue their education in a particular way, for example, entering the Pedagogical University. It should be noted that $13 \%$ were hesitant whether they would still study in the future which may indicate the reasons for the dissatisfaction with their current social status, and consider themselves best able to obtain a $\mathrm{PhD}$ Diploma. Besides, these $13.7 \%$ were also hesitant about their future teaching perspectives confirmed by our hypothesis as there is no such opportunity today.

The majority of the students within Group I (84\%) noted that they experienced a difference in professional activity between colleagues with a Junior Specialist Degree and those who acquired or already have a Higher Nursing Education - a Master's Degree in Nursing. However, 10\% did not agree with this statement, because Nurses in the same position perform the same tasks. And $6 \%$ of respondents could not determine the answer. This confirms the urgent issue that Health Managers need to understand the importance of the role of Nursing and introduce the necessary legal changes as soon as possible.

At the same time, $50 \%$ of the Nurses with Master's Degree who work in the hospitals indicated, that after the acquisition of Higher Education the attitude of their colleagues and their immediate surroundings have gradually changed: $10 \%$ were able to change their place of work; $7 \%$ managed to acquire a higher position; 33\% indicated, that they didn't note any changes within the described fields of life.

Among the Teacher Nurses with Master's Degree about $60 \%$ managed to take a higher post because most of them worked on lower positions such as laboratory assistant of the Department, etc. The remaining $40 \%$ have even changed their places of work or found better career perspectives. In accordance to these facts we assume that acquiring a higher qualification by continuous education improves both the career prospects and attitude of the colleagues and close friends or family members.

Participants were asked to identify the fields of their highest competence from a few selectable options. As a result, it was found that all respondents were competent to carry out Nursing work. In particular, respondents in Group I 38\% marked the ability to be in charge of a Nurse Unit of subordinates; only $4 \%$ have chosen a teaching capability. $90 \%$ of Group II respondents claimed to be able to manage and govern a Nursing Duty in a Medical Institution; about $30 \pm 5.5 \%$ have even carried out a Teaching Practice. At the 
same time, every single member of Group III identifies her/himself as a capable Manager of a Nursing Unit, as well as a good teacher.

It should be noted, that $100 \%$ of Groups II and III respondents confirmed a gradual substantial increase in their level of knowledge and skills after getting a Master's Degree in Nursing which enables them to claim to be a Specialists of a "High" level (highly qualified).

Everything said above confirms the hypothesis of this research in the aspect, that a Nurse with Master's Degree is a highly skilled Specialist who has acquired in-depth special knowledge and skills; has experience in their application in a particular field of Medicine which enables such a Specialist to be a capable manager, complier and leader of his/her specialty [6]. Nevertheless, the aim of training of a Nurse with Master's Degree differs from Bachelor Degree and Junior Specialist Nurses training. Nowadays, even the aid models of Nurse with Master's Degree and the Junior Specialist Nurse are completely different [11].

Currently about $73 \%$ of Nurses with a Master's Degree are trying to move away from the outdated form of behavior with the patient, and use the new philosophy of Nursing care and new approaches to its implementation. At the same time, $72 \%$ of Junior Specialist Nurses use the obsolete model pf professional behavior.

In our opinion, first of all, it is necessary to change the perception of the possibilities of Nursing work for Physicians and to teach them to work in parity in accordance to the parameters of the new model with Nursing staff. Secondly, the content of the functions of the Nurse should be changed in the practical health care depending on the educational and qualification level, the standards of loading and equipment. To do this, the coordinate between changes in the system of step Nursing Education and human resources provision of the Health
Care System is strongly required. This idea was supported by the results of the following research: 58\% from Group I considered Degree-based Medical Education to be perspective according to their point of view: as well as $80 \%$ of Group II and $100 \%$ of Group III participants. Still, $32 \%$ of Group I, $20 \%$ of Group II and $10 \%$ of Group III surveyed individuals do not see the possibility of realizing these prospects in practice.

In Western countries there is a positive experience in terms of multi-level (step-bystep) training of Nurses and the functions they perform in corresponding positions (Specialist for Medical Care Work depending on the specialization of the Institution; the Nurse of the In-patient Department; Family Doctor; ;Senior Nurse; Deputy Chief Doctor of Nursing; a Nurse involved in scientific and pedagogical activities), therefore the expediency of changes in the national system of training Nurses and staffing of health facilities is not in doubt. $[10,13]$. $76 \%$ of respondents in Group I confirmed the necessity of such; $83 \%$ of Group II; $100 \%$ of Group III have chosen the corresponding options in the survey as well. In total, $82 \%$ of surveyed participants approved the implementation of the Healthcare System changes and usage of step-bystep training principles; while in terms of management, people are always opposed to changes. This proves that the situation in the practical healthcare (staff dissatisfaction, lack of motivation to work effectively) can not remain the same in the future.

The majority of every Group's respondents has noted that while studying at a Medical Institution, their teacher/mentor of Clinical Specialties was a Nurse with Master's Degree. «Yes» was the answer of $84 \%$ of Group I («NO» - answered 16,0\%); in Groups II and III the answers percentage was: «yes» $-100 \%$. So, practically all respondents imagine the role of the Nurse with Master's Degree as a teacher. 
It is considered correct that the discipline "Nursing Care for Patients" and "Clinical Nursing" in a Medical Educational Institution should be taught by a Nurse with Master's Degree instead of a Doctor by $98 \%$ of Group I and $100 \%$ of Groups II and III respectively. In general, $98 \%$ of the sample (95 respondents) confirmed the correctness of this decision.

All surveyed respondents confirmed that the Nurse with Master's Degree has the benefits of being a Mentor for practicing Nurses. And also, on the question of whether a graduate education in the specialty «Nursing» helps to take an active part in Scientific Nursing Conferences, all 100\% in the three Groups undoubtedly gave a positive response.

Members of Groups I and II agreed on urging the necessity of gradual knowledge level updates due to never stopping scientific and technological progress in the medical sphere. Besides, they differentiatedly identified topics and fields for which it would be useful for them to conduct a special training within their professional activities. It is important to note, that the majority of Group I (46\%) showed a particular interest in new models of Nursing; 37\% of Group II offered their own set of topics which can be generalized as «Nurse as a Manager». It highlights the difference in level of education of surveyed individuals.

All respondents within Group III supported the necessity of international experience exchange and distinguished its benefits in solving educational and clinical issues of Nursing.

Surveyed individuals from Group I would delegate teaching professional training to the Nurse with Master's Degree (96\%) and to the Senior Nurse of the Department (4\%). Groups II and III consider it to be a duty of an MD Nurse only. Not a single participant of survey would like to see a practicing Doctor at this post which indicates the decisive role of the Nurse with Higher Education in the organization of the work of Nursing and training Nurses as well. The total survey score on this point was $98 \%$ which confirms that both Nurses and Nurses with Master's Degree are currently aware of the positive moments of graduate education, the opportunity to acquire the relevant competences that will enable them to be able to realize their potential and ambitions in the future in the fields of their professional activities. The changes that all respondents expect from the implementation of reforms in the Medical Sector - is the legislative regulation of the demarcation of the functions of Nurses and positions in Medical Institutions in accordance with their educational qualification; decent salary; the opportunity to obtain foreign work experience; to engage in scientific activity; as well as the possibility to get the appropriate degree and/or qualification. Consequently, getting full higher education by a Nurse together with the appropriate educational qualification level indicates the formation of the intellectual qualities of the Nurses with Master's Degree which determine the development of the person as an individual and give them the right to work in corresponding prestigious positions. MD Nurses play an important, even crucial role in the organization of Nursing activities and training.

\section{Conclusions}

It is confirmed, that the Nurse with Master's Degree is a highly skilled and qualified Specialist, who has received advanced special knowledge, skills, and training, as well as possesses the necessary experience matching her/his application which enables such an individual to act as the organizer and leader of Nursing within the particular Medical Institution and/or sphere of Medicine. 
We consider unacceptable the fact that most of Nurses-teachers with Master's Degree do not work in Medical Institutions and don't have the opportunity to constantly improve the professional level in the specialty of Nursing.

Specialists of Nursing in Ukraine consider that the time has come to implement the concept of the development of Higher Nursing Education and insist on the creation of certain favorable conditions for continuing education and obtaining the third educational-scientific level - PhD.

\section{References}

1. BAITSYM A, IU IN A IU, BAITSYM D R, TUHAROV I IA, KRYNYTSKA (2015) Current

2. role of mid medical personnel in the health care system / Nursing. - 2015. - №4. - P. 1114.

3. BANCHUK M V (2013) Development and reform strategy of Nursing in Ukraine Ukrainian Scientific and Practical Journal Zhitomir: Polissya. - 2013. Issue. 1. P. $18-21$.

4. WHO Report \& quote; World Health Statistics \& quote; [digital source]. - Access mode: http://

5. www.who.int/gho/publications/world health_statis6 tics/EN_WHS2 012_Full. pdf.

6. KOPETCHUK V A (2009) Theoretical and pedagogical aspect of improving the

7. professional training of Nurses with Master's Degree, Ukrainian Scientific and Practical Journal / Master of Nursing. - 2009.Issue 2.- P.19-23.

8. LATYSHEV E S (2012) Organizational structure and organizational activity. Manager skills. Communications, Management of the Health Protection Institution. - 2012. - Issue 8. - P.-85-104.

9. MAKHNOVSKA I R (2011) Formation and Evolution of Graduate Nursing. Education in Ukraine Journal of Zhitomir State University. Issue.60. Pedagogical sciences. Zhitomir. -2011. - P.154-158.

10. MINISTRY OF HEALTH OF UKRAINE [digital source]. - Access mode: http://www. moz.

11. gov.ua/ua/portal/.

12. WHO (1983) Resolution of the Assembly of the WHO 36.11 session 36 of WHO (1983) [digital source]. - Access mode: http:/ / www.who.dk/document/e71523R.pdf.

13. WHO (1989) Resolution of the Assembly of the WHO 42.27 session 42 of WHO (1989) [digital source]. - Access mode: http:/ / www.who.dk/document/e71523R.pdf.

14. HORANCHUK V V (2012) Improvement of methodical approaches to the training of healthcare managers on issues of quality management of medical care, Modern medical technologies.-2012. Issue 1.- P. 18-20.

15. HRYHOLA O H (2007) The urgency of reforming Nursing education in accordance with the principles of the Bologna process.-2007. - Issue.11.- P.24-26.

16. SINELNIKOVA L F (2011) Modern Nursing education in the conditions of integration of Ukraine into the European educational space. Ukrainian Scientific and Practical Journal,-2011. - Issue 1. - P.52-56.

17. BUCHAN J, CALMAN L SKILLMIX (2005) Policy Change in the HealthWorkforce: Nurses in Advanced Roles. - Paris: OECD, 2005. $63 \mathrm{p}$.

18. STROMBERG A, MARTENSSON J, FRIDLUNDB (2001) Nurse_led heartfailure clinics in Sweden/Eur J Heart Fail. 2001. - 3. - P. 139-144.

19. KARLBERG I at al (2008) MANAGING CHRONIC CONDITIONS Experience in Eight Countries. - Copenhagen: European Observatory on Health. Systems and Policies, 2008. - $181 \mathrm{p}$.

20. SHATYLO V I (2010) Reforming Nursing Education in Ukraine Ukrainian Scientific and Practical Journal: Polissya. 2010- P.1416. 